\title{
Research on the Distribution and Scale Evolution of Suzhou Gardens under the Urbanization Process from the Tang to the Qing Dynasty
}

\author{
Tiantian Zhang ${ }^{1, *(\mathbb{D})}$ and Zefeng Lian ${ }^{2}$ (D) \\ 1 Department of Landscape Architecture, School of Architecture, Soochow University, Suzhou 215006, China \\ 2 Department of Landscape Architecture, School of Architecture and Urban Planning, Suzhou University of \\ Science and Technology, Suzhou 215011, China; 1610124@tongji.edu.cn \\ * Correspondence: tiantzhang@suda.edu.cn
}

Citation: Zhang, T.; Lian, Z.

Research on the Distribution and Scale Evolution of Suzhou Gardens under the Urbanization Process from the Tang to the Qing Dynasty. Land 2021, 10, 281. https://doi.org/ 10.3390/land 10030281

Academic Editor: Luís Carlos Loures

Received: 17 February 2021

Accepted: 1 March 2021

Published: 10 March 2021

Publisher's Note: MDPI stays neutra with regard to jurisdictional claims in published maps and institutional affiliations.

Copyright: (c) 2021 by the authors. Licensee MDPI, Basel, Switzerland. This article is an open access article distributed under the terms and conditions of the Creative Commons Attribution (CC BY) license (https:/ / creativecommons.org/licenses/by/ $4.0 /)$.

\begin{abstract}
Suzhou city was the cultural centre of ancient south China. It continues the urban pattern of more than 800 years ago. Suzhou gardens are the essence of Chinese gardening art, as well as the valuable world cultural heritage site. This paper compared the evolution in the distribution and scale of Suzhou gardens among five historical periods, and discussed the influence of urbanization on gardening. It revealed that: (1) The distribution of Suzhou gardens was affected by the layout and changes of the political centre and commercial centre of Suzhou city; (2) The scale of Suzhou gardens was mainly affected by the available land scale within the city and the wealth of its owner; (3) The cityscape of 'half city occupied by gardens' was largely resulted from the rapidly increasing number of small courtyard gardens in the Qing Dynasty; (4) The evolution of Suzhou gardens' distribution and scale affected interior layouts. The evolution and social development of ancient cities can affect the distribution and scale of gardens. At the same time, the popularization of gardening art also optimizes the cityscape.
\end{abstract}

Keywords: Suzhou city; classical gardens; garden distribution; garden scale

\section{Introduction}

Suzhou is located in Jiangsu Province of China and has a history of over 2500 years. As early as the Song Dynasty (960-1279), people used the proverb 'heaven above, Suzhou and Hangzhou below' [1] to describe the most two prosperous cities in southeast China, both of which were beautiful, rich, and eminently livable. The unique 'eight water-land gates' feature of Suzhou city were established in the 9th century [2]. It was not until 875 (towards the end of the Tang Dynasty, 618-907) that the " shape of the city and the chessboard form of canals and alleys were formed and remain to the present day [3]. Today, there are a lot of historical sites such as ancient gardens, temples, and bridges in Suzhou. The poet Shen Chaochu (1649-1702) of the Qing Dynasty (1636-1912) described the cityscape in the poem Recalling the South Yangtze-Spring Tour as 'nice Suzhou, half the city was occupied by gardens', emphasizing the interdependent spatial relationship between the city and gardens. From the Tang to Qing Dynasties, the location, scale, water source, and artistic level of Suzhou gardens were influenced by the development of the city [4]. Gardens were described as 'wooded hills in the city' [5] and became a significant component of Suzhou cityscape and life element in the Ming (1368-1644) and Qing Dynasties [6]. However, the perceptual description was not enough to explain the formation mechanism of the relationship between Suzhou city and gardens. In recent years, some researchers have noticed this issue and discussed it.

Jen-shu believed that during the upsurge of 'garden fervor' in the Ming and Qing Dynasties, Suzhou gardens had become a symbol of status and wealth, meanwhile, the factors of cost, available land, location, land transaction, and water source were inevitable 
considerations when planning gardens [7]. Yinong thought the boundary was one of the most fundamental factors determining the spatial form of the Suzhou gardens, and garden boundaries were influenced by the development of the city [8]. Jing thought the change of the urban function and the urban population increase were the main reasons for the change in distribution and scale of Suzhou gardens in the Qing Dynasty [9]. Yong defined the 'half city occupied by gardens' as a 'gardenization' of Suzhou city, and it was related to that Suzhou became the most important commercial city in China during the Ming and Qing dynasties [10]. Chen thought that the large population growth would reduce the per capita building area, which led to the change of the spatial layout of Suzhou gardens in the Ming and Qing Dynasties [11].

Some studies focus on a certain garden's change of morphology, boundary, layout, image, and artistic level in different epochs, but less on the evolutionary relationship between garden and city. Guangcan et al. thought the expansion of urban roads was a reason for the spatial layout evolution of the Yi Garden [12]. Tian and Hai Fang compared the existing Lion Grove Garden with paintings of it from the Yuan Dynasty (1260-1370), then drew the outline of its initial construction in the 14th century. They found that its existing scale and layout, especially its boundary contiguous to the city, are different from those in the Yuan Dynasty [13]. Tiantian et al. took the Canglang Pavilion as an example and argued that the location of gardens in the city had prominent influences on their existence and continuation in the city [14].

Based on historical data of Suzhou's local history, garden essays and garden paintings, this study focus on the evolution and scale of Suzhou gardens from the Tang to the Qing Dynasty by comparing gardens in different periods, and explores the urban social factors that promote this evolution. This study helps to understand the internal evolutionary dynamics of ancient Chinese garden heritage. At the same time, it also helps to understand how Suzhou, a high-density ancient Chinese city, formed a 'half city occupied by gardens' urban pattern under the process of urbanization.

Figure $\mathrm{S} 1$ shows the indicative timeline for the period corresponding to the dynasties. As well as the detailed information of garden owners and others can be seen in Table S1.

\section{Materials and Methods}

This study rests upon first-hand historical materials which can be categorized into four types: ancient maps, collected from Local Chronicles Archives of Suzhou, showing the situation of waterways, streets, and important buildings; local Chronicles of different periods, collected from the local chronicles archives of Suzhou Library, showing the brief status of gardens (usually including information on scale and distribution), and urban population information, etc.; ancient paintings of the cityscape, such as the detailed panoramic painting of the ancient Suzhou city in the 18th century, collected from Duxiu Academic Search Platform; classical garden stories (garden records) by literati, collected from Local Chronicles Archives of Suzhou, usually contains detailed information about the garden, including the identity of the owner, construction motivation, cost, scale, layout, etc. Meanwhile, this study also draws on the experience and results of predecessors, such as unified and rectified Suzhou ancient maps, collected from Digital Resource Database of Suzhou Library; survey maps, collected from the local chronicles archives of Suzhou Library; secondary publications, such as collected garden stories, collected from the local chronicles archives of Suzhou Library, and indexing data of Suzhou Garden and Greening Administration Bureau, collected from Suzhou Garden Archives.

The analytical framework of this paper is organized around three important aspects: distribution evolution, scale evolution, and urban development. Taking time periods from the Tang to Qing Dynasty as clues, we marked the distribution of Suzhou gardens in different periods on calibrated ancient maps, and compared them; we collected the scale records of Suzhou gardens in different periods; finally, we discuss the impact of urban development on the first two changes. 


\section{The Evolution of the Suzhou Private Garden Distribution from the Tang to Qing Dynasty}

The different scales and drawing principles of Suzhou maps in different dynasties make it is difficult to compare. To improve the readability and visualization, we need to calibrate the ancient maps of different dynasties. Suzhou ancient maps of Song, Ming, and Qing Dynasties were already provided by Weizu Qu taken canals and bridges as references [15]. These maps are 'Canal map of the Song Dynasty' (Figure 1a), based on the 'Map of Pingjiang' in the Song Dynasty (Figure 2a, finished in 1229, the oldest Suzhou city map ever found [16]), the 'Canal map of the Ming Dynasty' (Figure 1b) based on the 'Map of Suzhou inland canal' in the Ming Dynasty (Figure 2b, finished in 1636), and the 'Canal map of the Qing Dynasty' (Figure 1c) based on the 'Map of Gusu City' of the Qianlong period in the Qing Dynasty (Figure 2c, finished in 1745), respectively [17].
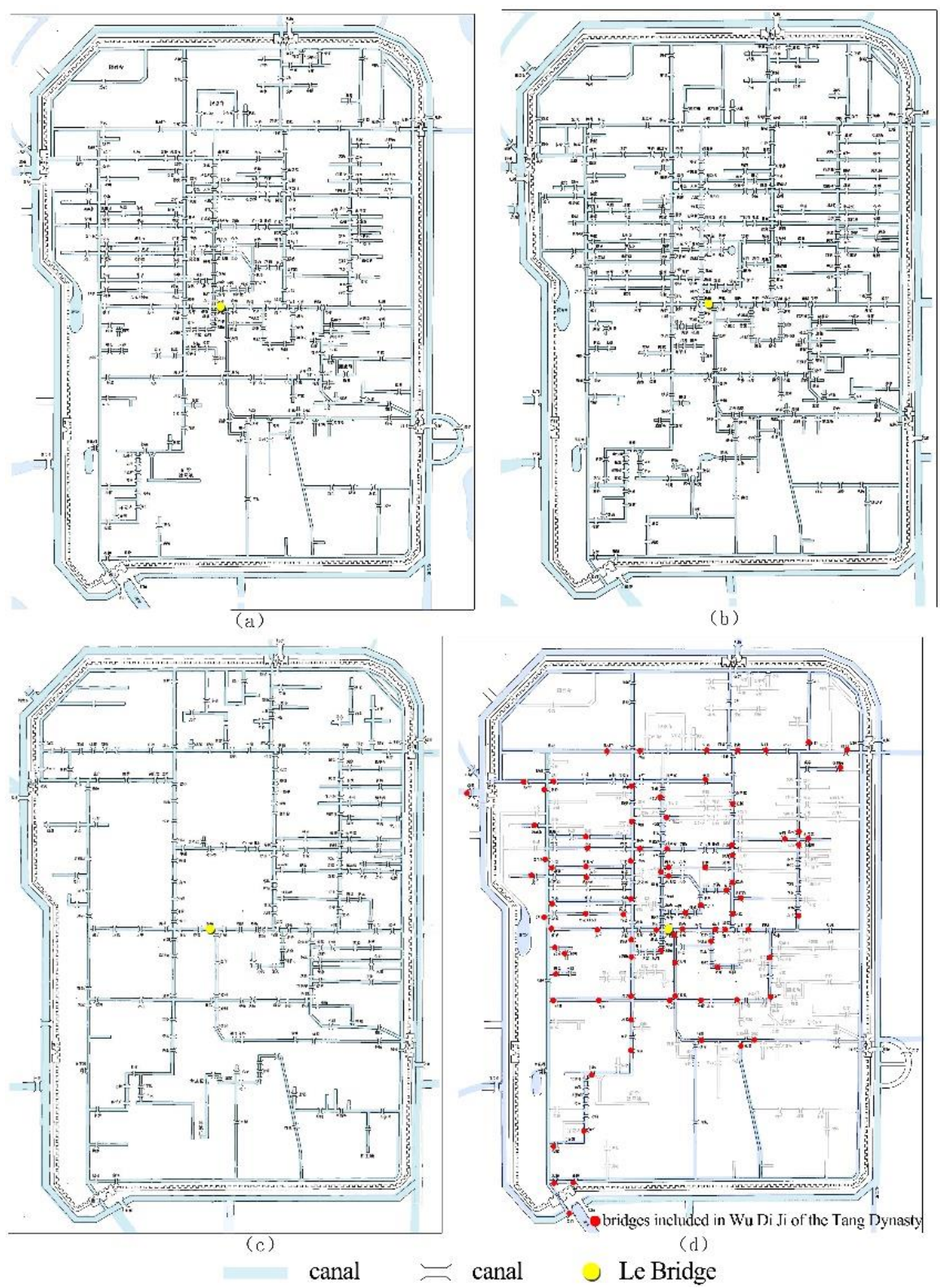

(b)

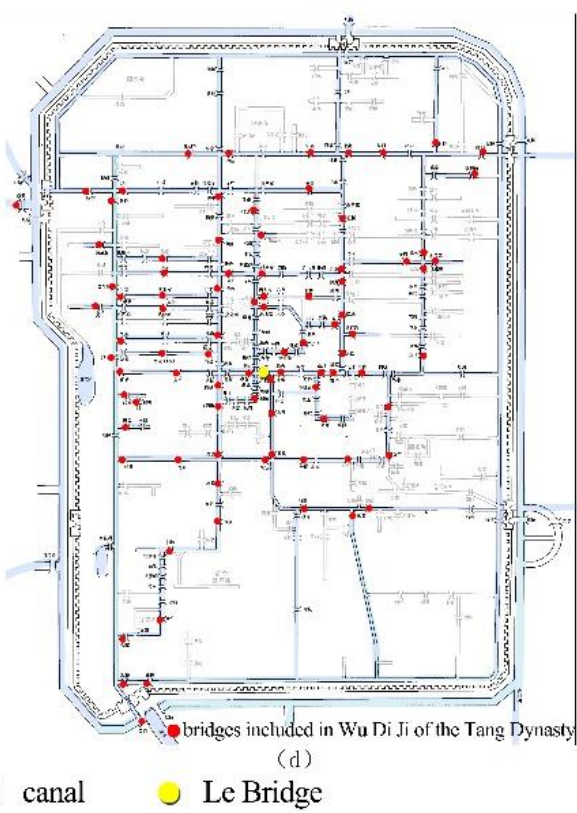

Figure 1. Canal maps of Suzhou in the Tang, Song, Ming and Qing Dynasties. (a) Canal map of the Song Dynasty. (b) Canal map of the Ming Dynasty. (c) Canal map of the Qing Dynasty. (d) Canal map of the Tang Dynasty. 


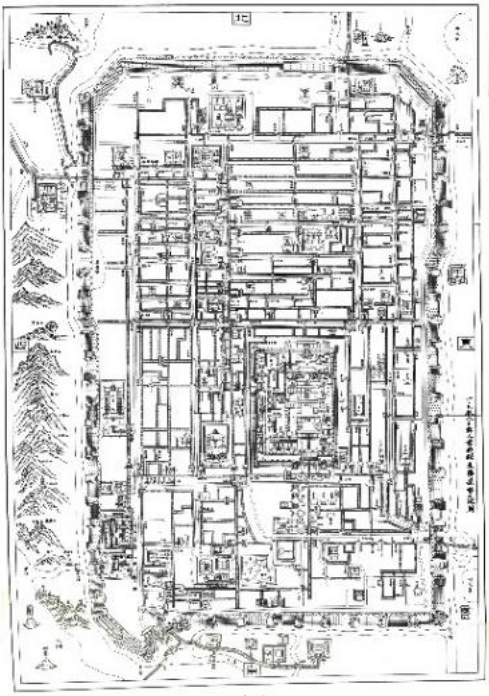

(a)
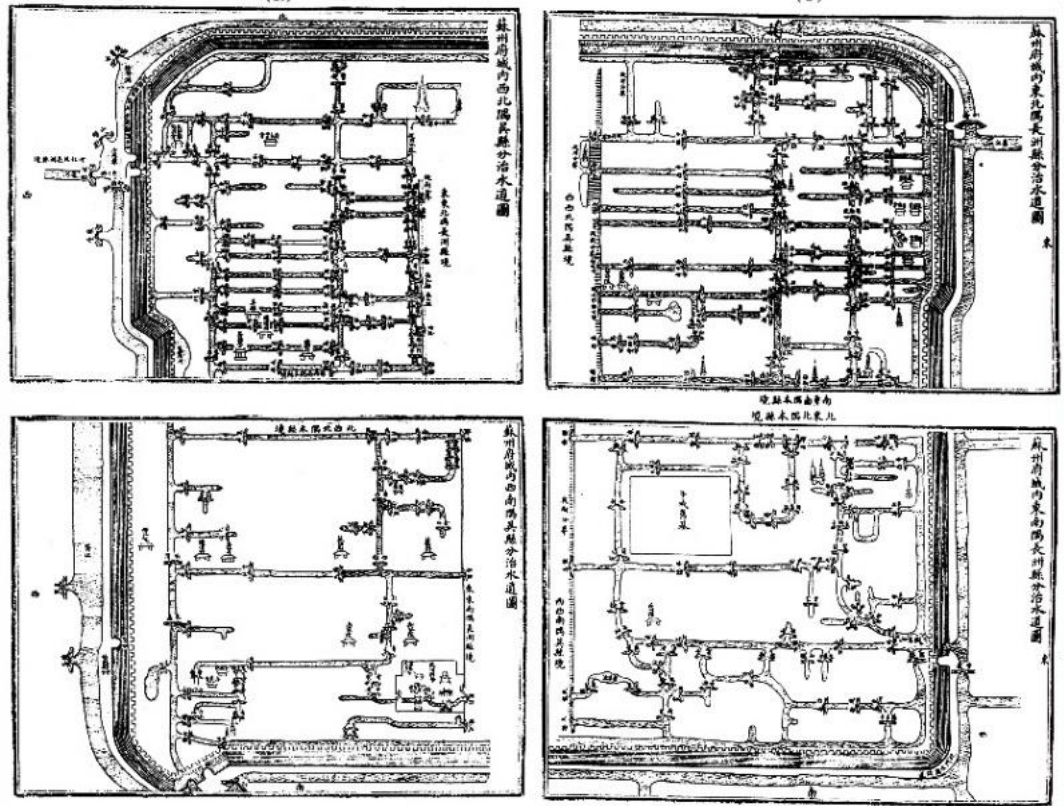

(b)

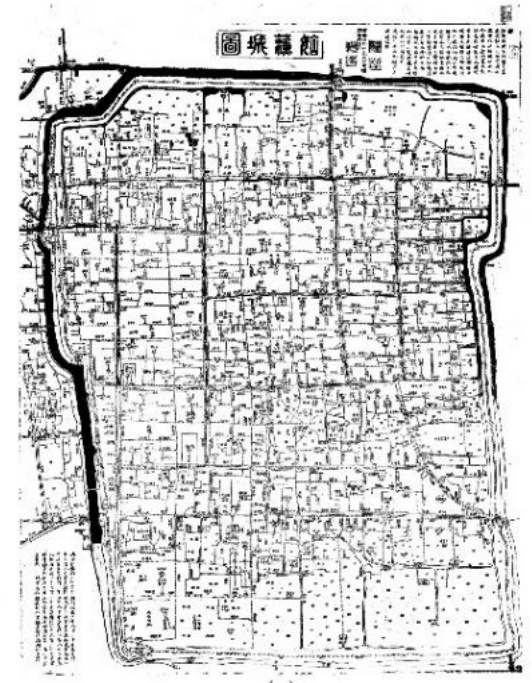

(c)

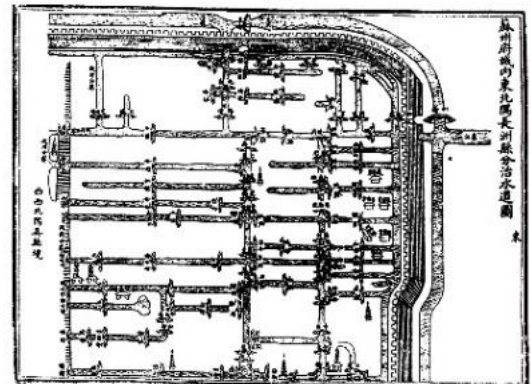

Figure 2. Suzhou ancient maps of the Song, Ming and Qing Dynasties. (a) Map of Pingjiang in the Song Dynasty. (b) Map of Suzhou inland canals in the Ming Dynasty. (c) Map of Gusu city in the Qianlong Period of Qing Dynasty

Due to the lack of Suzhou ancient maps of the Tang Dynasty, we overlayed the records of bridges and canals in Wu Di Ji (the local chorography of Suzhou in the Tang Dynasty) [3] (pp. 86-105) on the Canal map of the Song Dynasty and named it 'Canal map of the Tang Dynasty' (Figure 1d). Because Song Dynasty is closest to the Tang Dynasty. Secondly, because the Yuan Dynasty was too short, thus there was no Suzhou ancient map too. But its urban pattern was inherited from the Song Dynasty, so we used 'Canal map of the Song Dynasty' (Figure 1a) to represent the Yuan Dynasty.

Furtherly, we plotted private gardens and government buildings in different dynasties on their respective canal maps (Figure 3). Thus, for comparison, we employed a kernel density analysis in ArcGIS to express Suzhou private garden distribution (Figure 4). 

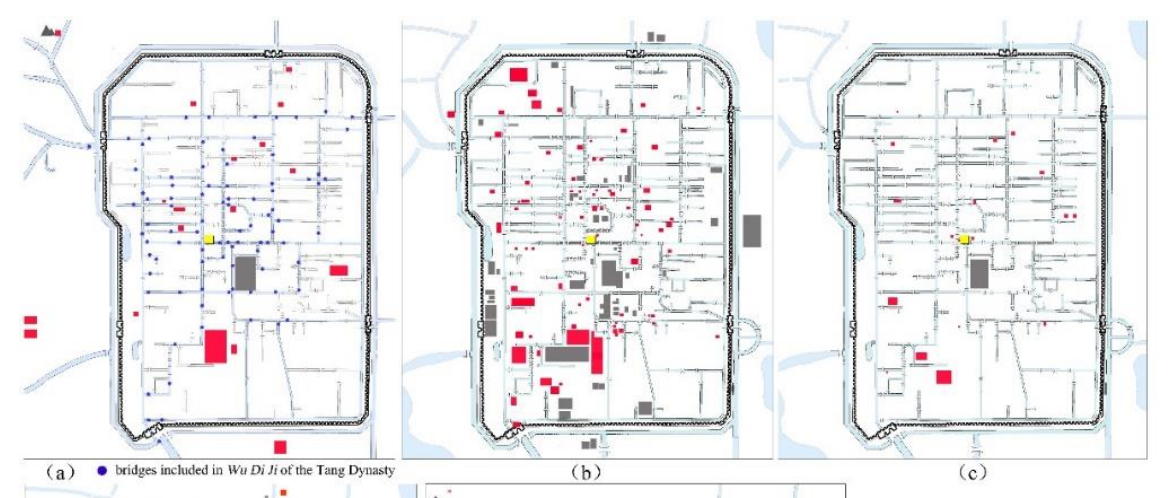

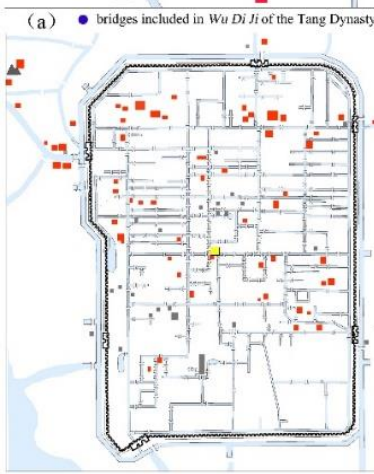

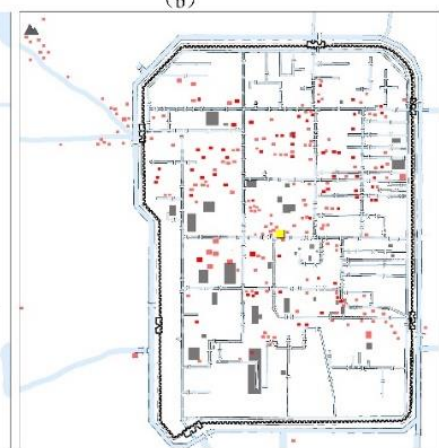

(c)

Figure 3. The distribution of government buildings and private gardens from the Tang to Qing Dynasty. (a) Tang Dynasty and the period of Ng- Yuih Kingdom. (b) Song Dynasty. (c) Yuan Dynasty. (d) Ming Dynasty. (e) Qing Dynasty.

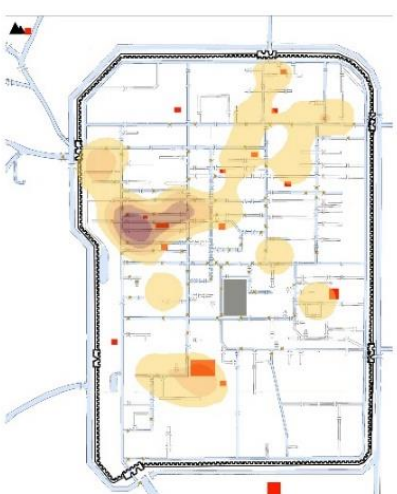

(a)

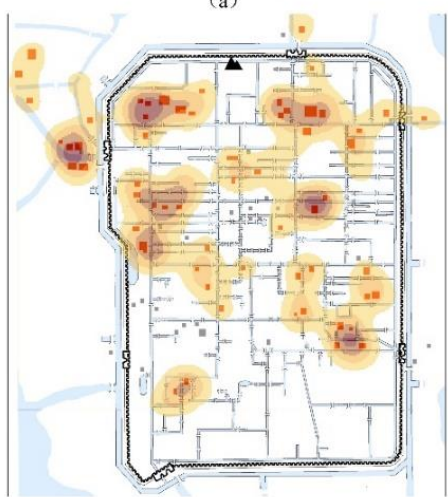

(d)

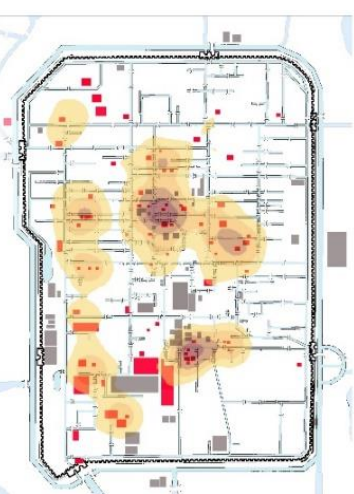

(b)

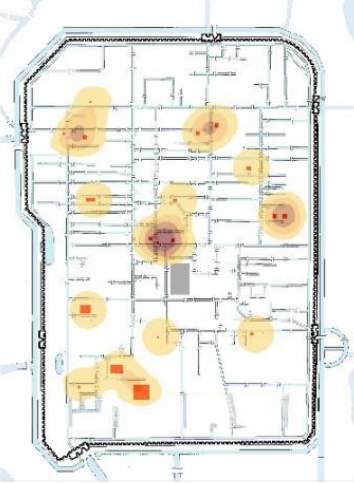

(c)

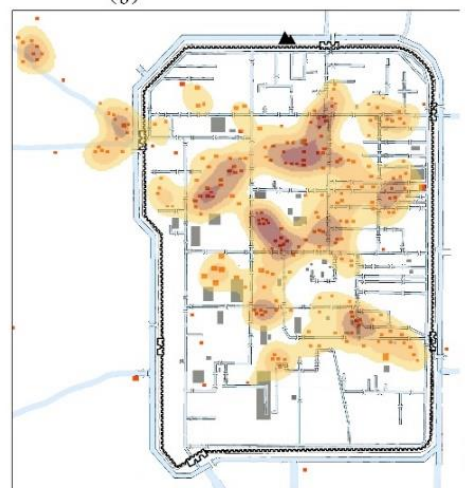

(c)

Figure 4. The result of kernel density analysis of Suzhou private gardens in different dynasties. (a) Tang Dynasty and the period of Ng- Yuih Kingdom (Search radius = 50). (b) Song Dynasty (Search radius $=150)$. (c) Yuan Dynasty (Search radius $=50)$. $(\mathbf{d})$ Ming Dynasty (Search radius $=150)$. (e) Qing Dynasty (Search radius $=250$ ). 
The Le Bridge was the center of the city since the Tang Dynasty ([1], p. 234). The castle (a small city within a large one, most castles were government offices in ancient China), located southeast of the Le Bridge, was the administration center from the Tang to the Yuan Dynasty. There was a vast amount of vacant land and farmland in the north and the south of the city, known as the North Field and the South Field, respectively. The east-west Ganjiang Road and the north-south Renmin Road are the dividing axes of the north-south and the east-west of the Suzhou city, respectively (Figure 5). From the Tang to Qing Dynasty, the number of canals in the north of Suzhou was always greater than in the south. From the Tang to Qing Dynasty, kernel density values of private garden distribution were higher in the northern part of the city than in the south. Compared to the Tang and Song Dynasties, in the Ming and Qing Dynasties, canals in the North Field and the South Field expanded and the number of private gardens increased. This situation was most likely due to the fact that water is necessary condition for gardens, and when choosing a site, garden owners would consider whether there was a canal to provide water. From the Tang to Qing Dynasty, the distribution of private gardens expanded from the city center toward the North Field and South Field; in the Ming and Qing Dynasties, it expanded outward from the city. In the Qing Dynasty, the number of gardens was the largest and the kernel density value was the highest.

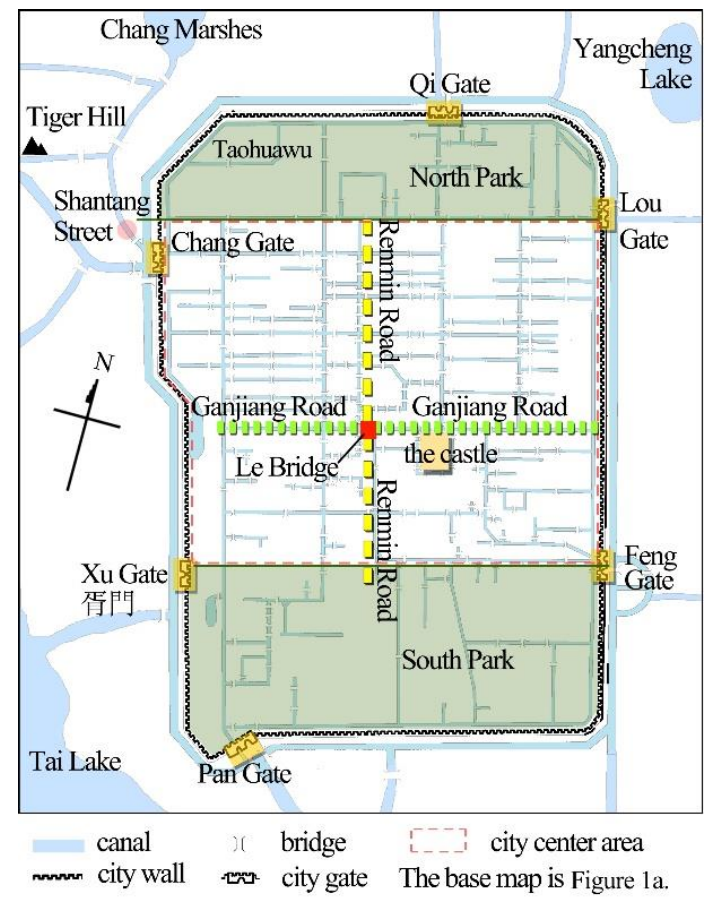

Figure 5. The layout of Suzhou city.

Due to its flourishing agriculture and handicraft industry, in 778, Suzhou became the only 'mighty prefecture' [18] and shipping center in south of the Yangtze River. According to regulations, regional chiefs of Suzhou in the Tang Dynasty, such as Li Ming (?-682), Wei Yingwu (737-792), and Bai Juyi (772-846), among others, lived and worked in the castle and did not build houses or gardens in other places. At that time, most urban private garden owners were hermits or retired officials (Table 1). They chose to build gardens in the north of the city, where transportation and life were more convenient than in the south. In the 10th century, Suzhou belonged to the Ng-Yuih Kingdom (907-978), which was governed by the Qian Family. They lived in the castle and built their gardens nearby, including three huge ones: South Garden, East Garden and Sun Chengyou's Garden, all located in the south of the city, where there was a lot of available land. 
Table 1. Recorded scales of Suzhou private gardens from 7th to 10th century.

\begin{tabular}{ccc}
\hline Name & Owner (Profession) & Description of the Scale \\
\hline Renhui's Garden & Ren Hui (a district defender) & a few mu [19] \\
South Garden & Qian Yuanliao (the prince of Ng-Yuih & Kingdom) \\
East Garden & Qian Wenfen (the son of Qian Yuanliao) & around 60 mu [1] (p. 191) \\
Sun Chengyu's Garden & Sun Chengyou (the brother-in-law of & the water pool covered dozens of mu [1] \\
(p. 187)
\end{tabular}

' $m u$ ' was a traditional unit of area in China. There was a slight difference in the area corresponding to $1 \mathrm{mu}$ in different ancient periods, roughly, $1 \mathrm{mu} \approx 666.67 \mathrm{~m}^{2}$.

The Suzhou government system in the Song and Yuan Dynasties, including the castle system, was similar to that of the Tang Dynasty [21]. The number of private gardens increased in the Song Dynasty to more than forty, some of which were small and mediumsized (Table 2). The large ones, like the South Garden of the Tang Dynasty, shrank by one-tenth and the rest areas were divided into a government school, Zhang's Garden, and Han's Garden in the Song Dynasty, forming a high-density garden area in the south of Suzhou city. A large newly-built garden in the Song Dynasty named Taohuawu Villa was located in the North Field, with an area of more than 700 mu. Meanwhile, most small and medium-sized gardens were located in the city center (Figure 3b). In the Yuan Dynasty, private gardens in Suzhou were mostly built in the countryside [22], and those in the city were mostly rebuilt on their old sites (Figure 3c): Shi Jian Shui Yin and Shu Jibo's Garden were both built on the old site of the South Garden; the Le Pu Lin Guan was built on the site of $\mathrm{Le} \mathrm{Pu}$, etc. Hence, the kernel density map does not show a different distribution law from that of the Song Dynasty (Figure 4c).

Table 2. Recorded scales of Suzhou private gardens in the Song Dynasty.

\begin{tabular}{|c|c|c|}
\hline Garden Name & Owner (Professions) & Description of the Scale \\
\hline Le $\mathrm{Pu}$ & Zhu Changwe (a government director) & more than $30 \mathrm{mu}$ [1] (pp. 193-195) \\
\hline Tongle Garde & Zhu Mian (a minion) & extremely vast [23] \\
\hline Taohuawu Villa & Zhang Jie (a grand preoeptor) & $700 \mathrm{mu}[24]$ \\
\hline Canglang Pavillion & Su Shunqin (a civil official) & around $30 \mathrm{mu}[25]$ \\
\hline Snail Cottage & Cheng Ju (an assistant magistrate) & $\begin{array}{l}\text { This house can only accommodate two } \\
\text { knees. Although it has a door, the } \\
\text { carriage can't get in. [1] (pp. 199-200) }\end{array}$ \\
\hline Han's Garden & Han Shizhong (a general) & \# around $200 \mathrm{mu}$ \\
\hline Zhang's Garden & Zhang Ziyan (a vice director) & \# around $150 \mathrm{mu}$ \\
\hline Yang's Garden & Yang Cunzhong (a general) & \# more than $100 \mathrm{mu}$ \\
\hline
\end{tabular}

The symbol '\#' indicates that the scale was estimated based on Map of Pingjiang.

Suzhou's military prowess greatly increased in the Song Dynasty. In addition to the original departments in and around the castle, the government built numerous military and official buildings during this period, including a nursing home, a government hospital, and a government school, among others [1] (pp. 50-96), improving the city function. The urban morphology theory of Cozens holds that the wall of the castle was a typical fixation line, which would affect the development of the entire urban plane [26]. The castle of Suzhou, as a 'core', affected the distribution of government buildings in the Song and Yuan Dynasties. On Map of Pingjiang, a part of government buildings and two garners at the South Street were arranged around the axis of the castle (Figure 6a,b) Government buildings were clustered around the castle, while there were fewer private gardens (Figure 3b). In 1367, Zhang Shicheng (1321-1367) set fire to the castle, and it was not rebuilt [27]. In the Ming and Qing dynasties, the southwest of Suzhou became the location of government buildings and the axle wire in Map of Pingjiang composed of government departments passed out of existence (Figure $6 \mathrm{c}, \mathrm{d}$ ). The distribution of Suzhou government buildings in the Ming 
and Qing dynasties had no axis to follow, and the distribution of private gardens changed (Figure 3d,e).

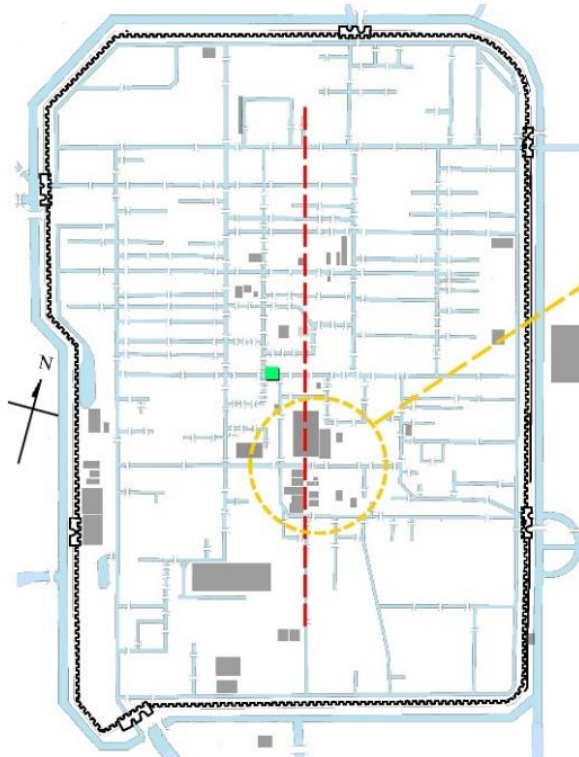

(a)

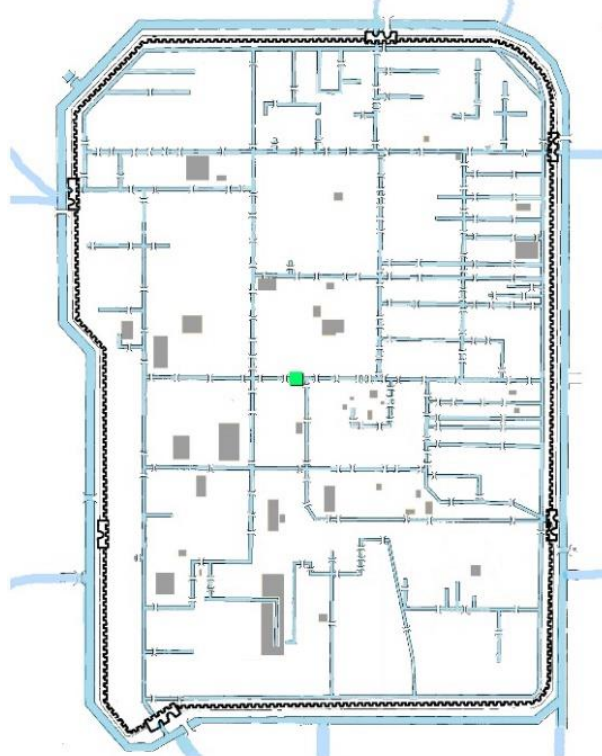

(c)

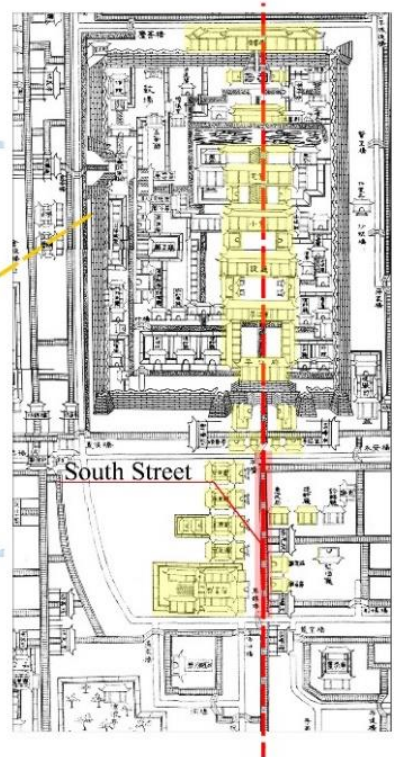

(b)

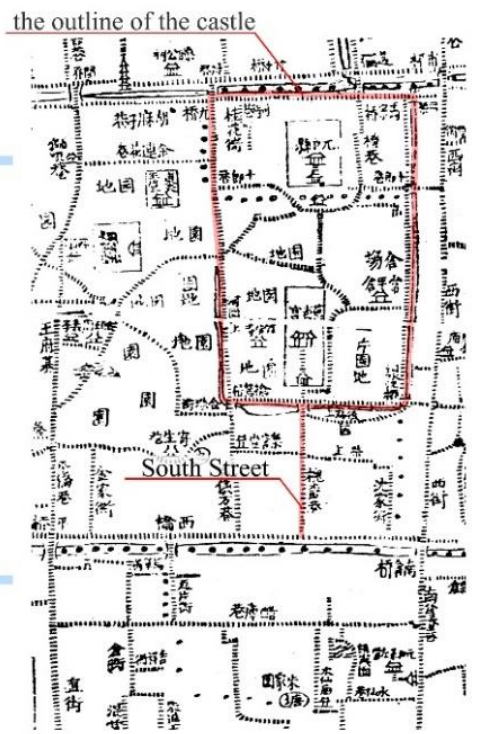

(d)

government building

Figure 6. The castle and its axis. (a) government buildings in Map of Pingiiang. (b) the castle and the axis. (c) government buildings in Map of Gusu City. (d) the fragmentized of the castle.

Unlike the high military status in the Song Dynasty, Suzhou gradually transformed into a handicraft and commercial city in the Ming Dynasty [28], and the northwest part of the city became the commercial center and expanded to the Shantang Street. Compared with the Song Dynasty, the number of newly built gardens in the Ming Dynasty increased, and those in the north of the city far exceeded those in the south. The private garden distribution expanded toward Shantang Street outside the Chang Gate after the mid-Ming Dynasty (Figure 3d). Meanwhile, areas around the Chang Gate and the Feng Gate became popular sites for private gardens. In the 'garden fervor', the owners of gardens in Suzhou during the Ming Dynasty were not only literati or bureaucrats of the upper class but also many merchants and less prosperous intellectuals (Table 3). For convenience, merchants 
preferred to build their gardens near the Chang Gate or Shantang Street, like the merchant Xu's Family: their gardens (such as the West Garden, the Lingering Garden, the Zizhi Garden, and East Manor) were all located outside the Chang Gate.

Table 3. Recorded scales of Suzhou private gardens in the Ming Dynasty.

\begin{tabular}{ccc}
\hline Garden Name & Owner (Status) & Description of the Scale \\
\hline Zhu's Garden & Family Zhu (unknown) & 200 mu [29] \\
East Manor & Wu Kuan (a minister) & $60 \mathrm{mu}[30]$ \\
Du Qiong's Garden & Du Qiong (an artist \& bibliophile) & less than 1 mu [31] \\
Feng Creek Cottage & Han Yong (an assistant minister) & several [32] $\mathrm{mu}[33]$ \\
Wan Pu & Qian Menghu (an artist) & more than 200 mu [34] \\
Humble Administrator's Garden & Wang Xiancheng(a censor) & a dozen of mu [1] (pp. 196-197) \\
Zi Zhi Garden & Xu Mochuan (a collector) & too small to accommodate two knees [35] \\
Huang Huang Zhai & Tang Chuanyin (a writer) & a water pool with an area of 2 mu [36] \\
East Garden & Xu Taishi (a government sub-director) & several mu [37]
\end{tabular}

In the Qing Dynasty, Suzhou city was not only the political center of Suzhou prefecture but the capital of Jiangsu Province, and it became the center of the Chinese handicraft industry and commerce. According to The Scroll of the Flourishing Times finished by $\mathrm{Xu}$ Yang in 1795 [38], buildings along both sides of Shantang Street were in tight rows, boats teemed in the water, and it was even more prosperous than the North Field and the South Field (Figure 7). The number of private gardens near the Shantang Street increased in the Qing Dynasty. At that time, most government departments were located in the southwest of the city, while gardens of literary families were clustered in the northwest near Chang Gate [39]. Therefore, in the Qing Dynasty the kernel density of private gardens in the southwest was much lower than in the northwest (Figure 3e). The number of private gardens (including courtyard gardens) in the Qing Dynasty in the literature was double that of the Ming Dynasty. From Figures 3e and 4e, we can see that in the Qing Dynasty, the number of private gardens in South Field was larger than that in North Field. Areas around the Taohuawu (see the northwest corner of Figure 5) in North Field were popular for private gardens in the Ming Dynasty, but became unpopular in the Qing Dynasty. This is because in 1659, the North Field was in ruins from the war, and the areas around the Taohuawu became fields and gradually fell into ruin [40]. After that, the North Field was less popular than South Field.

In the Tang and Song Dynasties, the castle influenced the distribution of government buildings. At that time, there was a lot of available land in the city for gardening, and the convenience of transportation and water resources were the main factors influencing the site selection of gardens. In the Ming and Qing Dynasties, there were more factors affecting the distribution of gardens. Merchants began to participate in gardening, and the garden ownership was no longer limited to the literati or officials, so that the distribution of gardens originally affected by the location of the administrative center began to be affected by the location of the commercial center as well. In addition, wars, water sources, etc. were still influencing factors. 


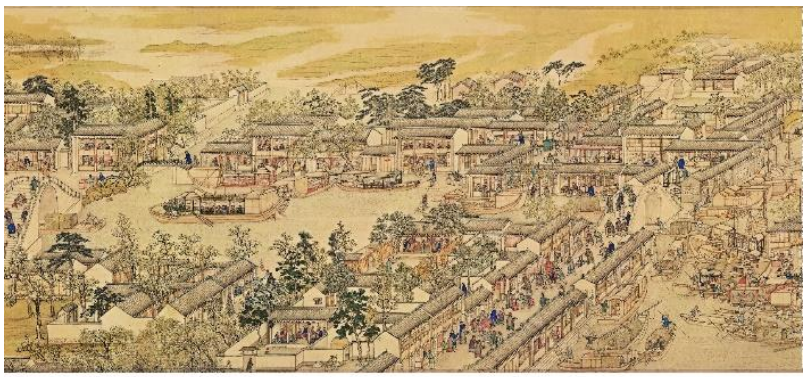

(a)

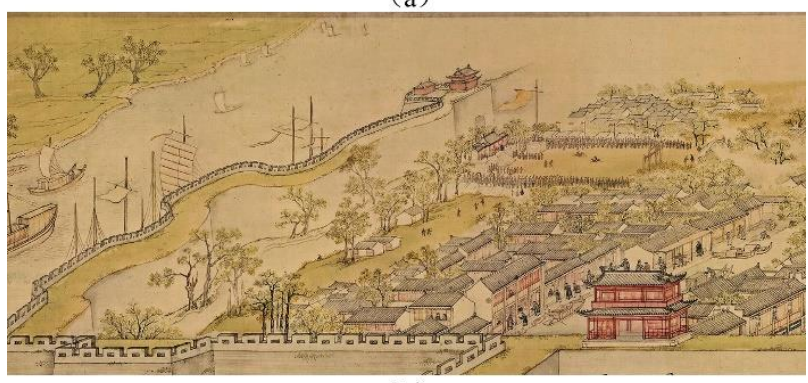

(b)

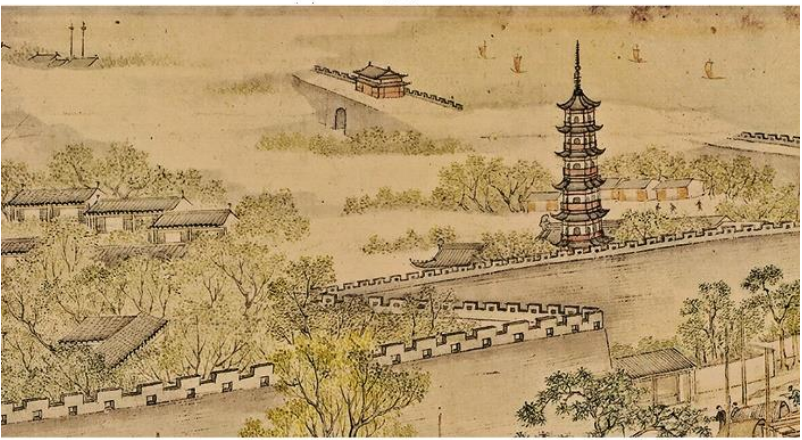

(c)

Figure 7. Three sections of The Scroll of the Flourishing Times. (a) Shantang Street. (b) the North Field. (c) the South Field.

\section{The Scale Evolution of Suzhou Private Gardens in Different Dynasties}

In some studies, Suzhou gardens are often described as small, delicate, and artificially constructed [41,42]. From garden stories and garden paintings before the mid-Ming Dynasty, we can see that the scale of many Suzhou private gardens could be as large as tens or hundreds of mu, such as the South Garden, the East Manor, Feng Creek Cottage, and the Humble Administrator's Garden, among others (Tables 1-3). These gardens were composed of large-scale natural elements, such as natural mounds, woods, and natural pools, with a loose spatial layout, and most of them were far from such descriptors as exquisite, artificial, or miniature ([1], p. 28). However, we can see most private gardens built in the Qing Dynasty boasted sophisticated layouts and a lot of artificial elements without natural elements to cope with their shrinking scale. What was the reason for the shrinking scale of Suzhou private gardens?

From the 7th to the 10th century, large private gardens with an area of tens of mu or more were all built by the Qian Family, such as the South Garden, which at around 35 ha was the largest one that has appeared in Suzhou city. In this garden, there were only 'three pavilions, eight high platforms, and two-storey buildings'; most of the garden consisted of mounds, ponds, and woods. In the Sun Chengyou's Garden, there was a mound, countless bamboo plants, and a large pond ([1], p. 187-189). The common feature of these gardens was their large scale with few artificial constructions. However, since the Song Dynasty, their base sites were gradually divided into small gardens and houses. In addition to the South Garden, Sun Chengyou's Garden also shrank into the Canglang Pavilion in the Song Dynasty. 
In the Song Dynasty, the scale of the newly built private gardens was uneven. Gardens built by dignitaries and important officials were still large (Table 2); however, compared with the previous dynasty, many small and medium-sized gardens built by literati appeared. As Liu Dunzhen said, the scale of gardens in the Song Dynasty was smaller than during the Tang Dynasty, but it was more exquisite and variable [43]. The shrinking of the garden scale was also reflected in their names, like Xiao Yin Tang (in Chinese, 'Xiao' means small; 'Yin' means seclusion; 'Tang' means the main room or hall of a house), Snail Cottage, etc. Scholars generally believe that the shrunken scale and the layout shifting to exquisite were related to the advancement of literati culture [44]. Gardens built by literati in the Song Dynasty, although only a few mu, still had natural elements, like groves and mounds. But the layout of rockeries, water pools, and buildings were more elegant than during the Tang Dynasty. In the Le Pu of Zhu Changwen, there were five types of buildings, a winding pool with three shapes, a hill, and a mound covered with woods [1] (pp. 193-195).

During the Yuan Dynasty, the largest newly built garden was the Lion Grove (around a dozen $\mathrm{mu}$ ) and the smallest one was Shi Jian Shu Yin (2 mu), most others were built on the sites of former gardens, such as Su Jibo's Garden, Green Water Garden, Xiao Dan Qiu, Le Pu Lin Guan, they were shrunken in scale comparing with their predecessors. Le Pu of Zhu Changwen in the Song Dynasty was $30 \mathrm{mu}$, in the Yuan Dynasty it shrunk to a few $\mathrm{mu}$, belonging to Zhang Shi (1330-1394), and in the Ming Dynasty, it shrank to less than $1 \mathrm{mu}$, belonging to Du Qiong ([27], p. 485).

The scale of newly built gardens in the Ming Dynasty ranged from several mu to hundreds of mu (Table 3), like the Humble Administrator's Garden, East Manor and Feng Creek Cottage built in the Ming Dynasty. They featured mounds, farmland, vegetable patches and orchards, and generally more natural elements than artificial ones [45]. Medium and small-sized gardens, such as Wan Pu [33], Qiu Zhi Garden [46] and Duo Mu Garden [47], covered an area ranging from several mu to tens of mu with more artificial elements, such as water pools, artificial hills, halls, pavilions and corridors. The smallest-scale gardens, which might be called courtyard gardens, were usually a few hundred square meters or smaller, such as Yu Pan Shan Fang [48] and Huang Huang Zhai [35] (Table 3), etc. They usually arranged a few plants, rockeries around a small water pool, a pavilion in the courtyard, or a gap around buildings, and did not employ all garden elements.

After the middle Ming Dynasty, the number of private gardens in Suzhou rose sharply, while the scale shrank. During the Qing Dynasty, the general scale of newly built Suzhou private gardens was less than $10 \mathrm{mu}$, such large-scaled private gardens as the Humble Administrator's Garden and East Manor, had never appeared in Suzhou city (Table 4). The Couple's Garden was the largest newly built private garden in the Qing Dynasty, covering an area of $7740 \mathrm{~m}^{2}$ [49], less than one-fifth of the Humble Administrator's Garden from the Ming Dynasty. Counting from the local chronicles and Suzhou cultural relics protection units, there were around 300 newly built private gardens in the Qing Dynasty, of which more than two- thirds were courtyard gardens. In these gardens, agricultural elements such as farmland, vegetable patches or orchards no longer existed and the water pools, the artificial hills, the pavilions, and the corridors were scaled down. In the Qing Dynasty, the gardening theory and technology had matured [50]. To save space and create a rich visual experience, a half-pavilion and half-gallery built against the wall frequently appeared in some courtyard gardens, such as the Bei Ban Garden. The Can Li Garden was the smallest one: its total area was $2390 \mathrm{~m}^{2}$ while the area of the courtyard garden was $140 \mathrm{~m}^{2}$. The small pavilion and small water pool, rockeries and trees were arranged in a well-designed layout that had sufficient spatial depth [4]. 
Table 4. Scale Table of Private Gardens in the Qing Dynasty.

\begin{tabular}{ccc}
\hline Garden Name & Owner (Professions) & Description of the Scale and Its Source \\
\hline Couple's Garden & Lu Jin (a prefect) & \# around $7740 \mathrm{~m}^{2}$ \\
Yi Garden & Gu Wenbin (an intendant) & \# around $4440 \mathrm{~m}^{2}$ \\
Ting Feng Garden & Wu Yun (a prefect) & around $1310 \mathrm{~m}^{2}$ \\
Qu Garden & Yu Yue (a litterateur) & \# total $3020 \mathrm{~m}^{2}$, garden area around $450 \mathrm{~m}^{2}$ \\
Shao Hua Study & Wang Wan (a litterateur) & sveral gong wide [51] \\
Tui Garden & Wu Jiaquan (a litterateur) & gong wide [52] \\
Zhu's House & Zhu Shou (an aide and staff) & the courtyard was 4 or 5 Chi wide [53] \\
Xiu Gu & Jiang Gai (a first-degree scholar) & the garden was less than ten hu wide [54] \\
Dong Zhai & Wu Yifeng (a bibliophile) & the garden was less than ten hu wide [55] \\
Shuang Ta Ying Garden & Yuan Xuelan (a bibliophile) & a little over $1 \mathrm{mu}[56]$ \\
Yi Garden & You Tong (a dramatist) & around $10 \mathrm{mu}[57]$ \\
Bei Ban Garden & Lu Xiemei (a circuit intendant) & around $1160 \mathrm{~m}^{2}$ \\
Chang Garden & Wang (a circuit intendant) & \# total 2820 $\mathrm{m}^{2}$, garden area around $1 \mathrm{mu}$ \\
Can Li Garden & unknown name (a salt merchant) & \# total 2390 $\mathrm{m}^{2}$, garden area around $140 \mathrm{~m}^{2}$ \\
\hline
\end{tabular}

1 gong $\approx 1.6 \mathrm{~m} ; 1 \mathrm{chi} \approx 35 \mathrm{~cm}$ in the Qing Dynasty. The 'hu' was a tablet held in front of the chest by officials when received in audience by the emperor. $1 \mathrm{hu} \approx 10 \mathrm{~cm}$, in this description, ' $10 \mathrm{hu}^{\prime}$ was an exaggeration, referring to its very small size. The symbol '\#' indicates that the data comes from the Suzhou Garden and Greening Administration Bureau.

\section{Discussion}

\subsection{How the Evolution of Suzhou City Affected the Distribution and Scale of Gardens?}

From the Tang to Qing Dynasty, the area of land within the Suzhou city wall changed little [58]. However, the exploding population in the Ming and Qing Dynasties put huge pressure on the land and the per-capita building area decreased. The total population of the Suzhou administrative region was around 300,000 in 1185 during the Song Dynasty [1] (p. 5). In the Hongwu period (1368-1398), the total population of Wu County and Changzhou County (two counties under the jurisdiction of Suzhou, including the ancient city) almost reached 860,000 [59]. Some scholars inferred that the population of Suzhou at that time was around 300,000 and during the Zhengde period (1506-1521), it was around 380,000 [60]. The population of Suzhou doubled in 200 years, which surely affected the scale of land use for private gardens within the city. The population of the Suzhou administrative region continued to grow in the Qing Dynasty: around 1644, the population stood at 1.38 million; in 1674, it was 1.43 million [61]; and in 1810 it was around 5.9 million [62]. Some scholars believe that the population of the ancient part of the city reached 700,000 in the early Qing Dynasty [63].

Suzhou inland canals were narrow, around $6.7 \mathrm{~m}$ wide [64] and bristled with hundreds of bridges, which eventually could not meet the overloaded population and the shipping demand. The preface on Map of Suzhou Inland Canals in the Ming Dynasty states that after the middle Ming Dynasty, the management of the inland canals was lax and a lot of them had silted up ([64], pp. 51-52). Many canals were marginalized or filled after being blocked, turned into roads, or occupied by houses in the Qing Dynasty ([15], pp. 119-123); meanwhile, numerous north-south alleys appeared, resulting in fragmentation of land; see the comparation between Map of Pingjiang (1239) and Map of Gusu city (1745) (Figure 8). Hence, large-scale building lots were practically nonexistent in the city center, and the land in South Field and North Field was gradually exploited. The north-south distance of two adjacent east-west roads was generally around or less than $100 \mathrm{~m}$, which determined the maximum north-south distance of a garden in the city center. Take the Couple's Garden and its surrounding plots as an example (Figure 9). The Couple's Garden was surrounded by water on its east, south and north sides, and had a length of $74 \mathrm{~m}$ from north to south. It could only expand its base site through the west. Hence, its garden area was arranged on the east and west sides. Houses on the left side of Figure 9 have the same north-south distance from the two adjacent waterways, and their widths east-west are narrow, usually less than $20 \mathrm{~m}$. This was the common form of Suzhou residences in the Ming and Qing 
Dynasties. Hence, in small base sites, gardeners could only use the gap of buildings or an expanded courtyard to build gardens.
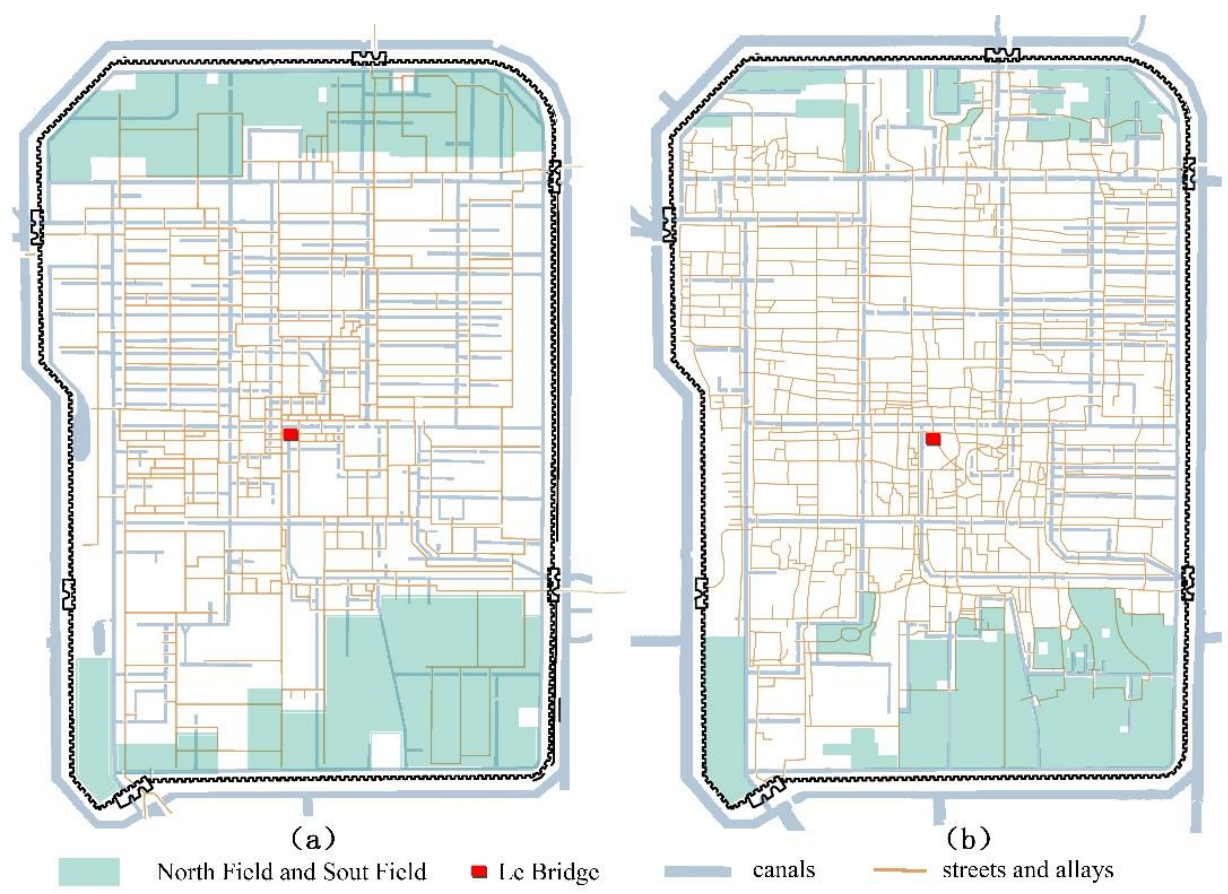

Figure 8. Comparation between Map of Pingjiang and Map of Gusu city. (a) the Song Dynasty (1239). (b) the Qing Dynasty (1745).

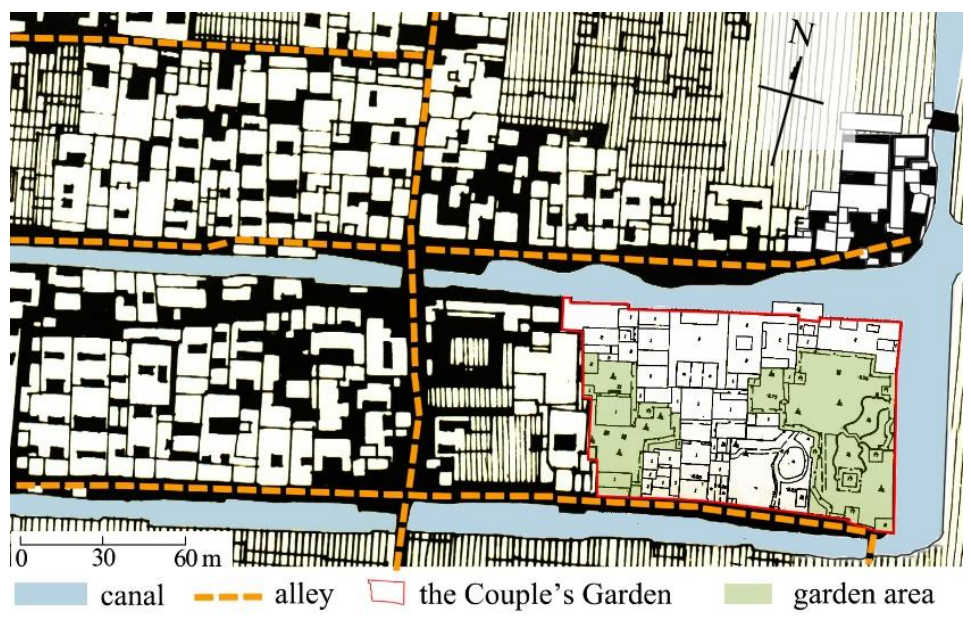

Figure 9. The Couple's Garden and the typical urban fabric of Suzhou.

In the Tang and Song Dynasties, owners of those large or extra-large-scaled private gardens were all wealthy and influential, as local rulers (such as Family Qian) or top ministers (Zhu Mian, Han Shizhong, Zhang Jie, etc.). After the middle of the Ming Dynasty, private gardens had become a symbol of wealth, no longer just an exclusive consumption of the top literati class or top officials. 'Garden fever' was born ([7], pp. 3-11). Merchants began to emulate literati and high-ranking officials to build gardens, because they had strong economic capability. With the maturity of gardening theory and technology, it was possible to create a rich and complex visual experience on a small plot. As the gardening costs decreased, ordinary merchants and literati who were not very rich or high-status could build a small courtyard garden in their home [65]. 
According to the scale, we divided Suzhou private gardens in the Qing dynasties into three types and selected a typical case plan for each one (Figure 10). The first type is the large garden, as the Humble Administrator's Garden, Lingering Garden, Lion Grove, Yi Garden, or Couple's Garden, which covered an area over ten mu. They had independent building and garden areas. Their garden areas usually included all the gardening elements, namely rockeries, water bodies, buildings, and plants of a certain scale and quantity. For example, the Yi Garden was completed at end of the 19th century. Its garden area was more than $4000 \mathrm{~m}^{2}$ and the building footprint was more than twice the size of it. The garden area of the Yi Garden had a collection of views from other well-known gardens: the prototypes of the double corridor on the east of the pool, the artificial hill, the shape of the pool and those white bark pines came from the Canglang Pavilion, the Mountain Villa, the Net Master's Garden and the Lingering Garden, respectively (Figure 10a) [66].

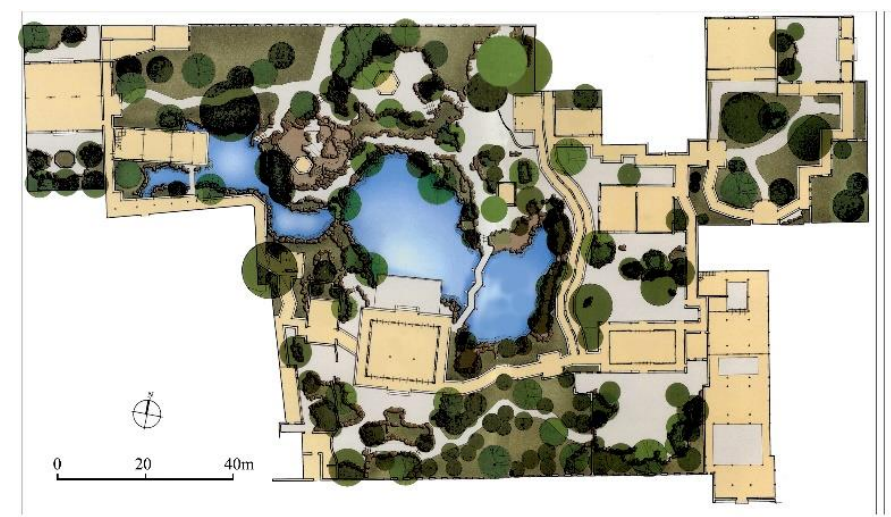

(a)

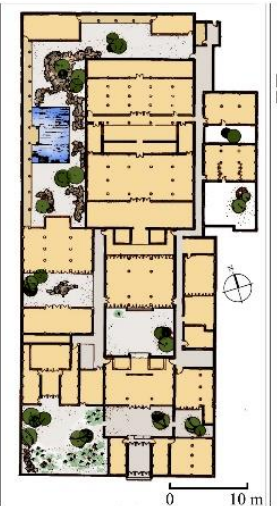

(b)

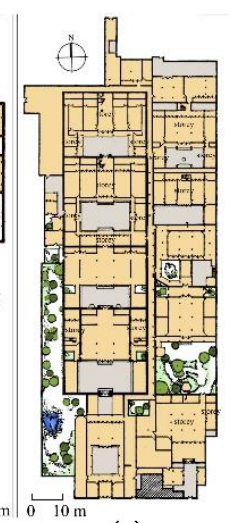

(c)

Figure 10. Three typical Qing Dynasty Suzhou gardens. (a) the Yi Garden. (b) the Qu Garden. (c) the Yang's House.

There was no more than a dozen of the first type of garden. Regardless of the size, the layout, the material of buildings and artificial hills were superb, becoming the wealth fought over by the powerful. Owners of these gardens were officials with the highest social status in Suzhou at that time. Chen Zhilin (a grand academician), Wang Yongning (the son-in-law of the Prince Wu Sangui), Jiang Qi (a prefectural chief), and others, were successive owners of the Humble Administrator's Garden; Huang Xingren (a prefectural magistrate) and his son Huang Xuan (an intendant) were owners of the Lion Grove; Lu Jin (a prefectural magistrate), and Shen Bingcheng (an intendant) were owners of the Couple's Garden. Gardens originally built in the previous dynasties usually had good bases, becoming the status symbol pursued by the top class and only belonged to this class. Ordinary people, small traders, or minor officials had no economic power to buy or build a large- or medium-sized garden. The Lingering Garden was originally built in the Ming Dynasty with a large water pool, artificial hills, and numerous buildings. In the Qing Dynasty, it belonged to Cheng Woyun, a hugely successful pawnbroker. Sheng Kang (1814-1902), a provincial administration commissioner, took a fancy to this garden and asked Gu Wenbin (1811-1889) to act as a middleman. Sheng used the criminal record of Cheng Woyun's nephew as a bargaining chip and forced Cheng to sell the Lingering Garden to him for less than one-tenth of the market price. As a businessman, Cheng's social status was much lower than Sheng and Gu's, so Cheng was forced to compromise [67]. Large scale, scarcity, exquisite design, and high social status of their owners were common features of this type of garden.

The second type was the dozens of mid-scale gardens, such as the Qu Garden, the Chang Garden, etc., which usually covered a total area less than ten mu, most of which were building areas. The garden area usually accounted for a small proportion, less than $2 \mathrm{mu}$, equipped with all kinds of gardening elements on a small scale. The social status or economic capacity of garden owners of this type, who were usually mid-level and minor 
officials, teachers, scholars, and rich merchants, was slightly inferior to the former type. They might have a good sense of aesthetics, but their economic capacity for gardening was limited. For example, Yu Yue, a noted scholar of the late Qing Dynasty, brought a piece of land and built more than 30 rooms, accounting for about $85 \%$ of the total area. Then he built a small garden in the gap. In this garden, there was a square pool of around $35 \mathrm{~m}^{2}$, a half-pavilion, a half-corridor, some rockeries, and a flowerbed (Figure 10b). He said that although the garden was small, it was not easy to build. Although the area of this type of garden was not large, its artistic value was generally recognized. Meanwhile, these gardens show the gardening skills on narrow plots of land in the Qing Dynasty.

The last type was the courtyard gardens, which were the most common in the Qing Dynasty. These gardens were attached to residential buildings, often creating small water pools, rockeries, half-pavilions and half-corridors in the courtyard or in the gap between residential buildings. Owners of this type of gardens were officials at the bottom: bibliophiles, ordinary merchants, and literati of limited means. At the end of the Qing Dynasty, actors and doctors, who were originally at the lower end of the respectable classes, also began to build gardens [68]. In the late Qing Dynasty, state organs and local bureaucrats were repeatedly set up, the number of civil officials exploded, and government institutions were bloated [69]. The financial allocation from the central government to the middle and lower levels of officials appeared to be minimal. Lower officials had to rely on their meager salaries to support their families, and it was difficult to build large or mediumsized gardens. Therefore, small gardens were built in the gap, or even a few stones, small flowerbeds, or bonsai trees placed in the courtyard. Take Yang's House as an example: it was bought by a jeweler named Yang Hongyuan in 1894 [70] (Figure 10c). The total area was around $8400 \mathrm{~m}^{2}$, the garden of the west gap was around $600 \mathrm{~m}^{2}$ and the east courtyard was around $300 \mathrm{~m}^{2}$. Meanwhile, some small courtyards with trees or stones were arranged in building gaps. The design of the west gap and east courtyard was different according to their different plot shapes. In the west long gap, the wall was used as the background for plants and rockeries, while in the east, the hall's architectural front porch was integrated into the courtyard, and some rockeries, a water pool, and a pavilion were designed. These small, scattered courtyards seemed to be a complete garden that had been split into several pieces.

We draw a diagram of the pyramidal relationship between the scale, owner status and the number of Suzhou private gardens in the Qing Dynasty (Figure 11). The maturity of gardening theory and technology made it easy for those who had relatively low economic capacity to build their own private gardens. Those private gardens that were large-scale, containing all kinds of garden elements and of a high artistic level, required not only high economic capacity but also a high social status of the garden owner. 'Half the city was occupied by gardens' was a phrase that described the experience of the cityscape; however, it is difficult to create such scenery with only a few large-scale gardens. Dozens of mediumand small- scale gardens and hundreds of courtyard gardens could be seen all over the streets and alleys, and they were the main factors prompting the integration of garden scenery into the cityscape.

large- and medium-sized/ the top class of society/ few people can own them.

medium- and small- size gardens/ middle level officials, upper - class literati or plutocrats/ a few people can own them.

small- size gardens and courtyard gardens/ low-level officials, low-income literati, ordinary businessmen/ many people with a certain economy ability can own them.

Figure 11. The pyramidal relationship between the scale, owner status, and the number of Suzhou gardens in the Qing Dynasty. 


\subsection{Limitations and Insights for Future Research}

Some limitations of this study deserve further discussion. Firstly, there may be omissions in the literature about ancient Suzhou city and gardens that we have collected. For example, information on gardens in the periods may be missed, which will result in the basic data we used for analysis, that cannot be absolutely accurate.

Secondly, this study generally used the Tang, Song, Yuan, Ming, and Qing Dynasties as the nodes of the research time, while the intervals of them are not even. For example, the Yuan Dynasty is particularly short. There were few newly built gardens in the Yuan Dynasty, so the scale and distribution of gardens did not reflect the characteristics at that time. Further, this study analyzed all the gardens built in each dynasty together but ignoring its change process. Future research can focus on a specific dynasty and a specific period time of it to obtain more accurate historical rules.

Thirdly, this study used ArcGIS to conduct kernel density analysis on the distribution of gardens in different periods, thus promoting our understanding of the evolution of the garden distribution. However, more quantitative analysis methods could be considered in future research. For example, studies can propose general indicators with metrics to quantify analyze the evolution of gardens. Thus, it can make the research more general interested and apply the methodology to the gardens in other countries.

Fourthly, qualitative variables could also be analyzed from the perspective of social sciences in future research. For example, studies can divide the variables that affect the scale of gardens into the scale of the available land in the city, the wealth of the garden owner, and aesthetic orientation at that time, etc. As well, divide the variables that affect the distribution of gardens into the distribution of available land in the city, profession and workplace of the garden owner, urban business districts distribution, and urban water resources distribution, etc.

\section{Conclusions}

The land area within the city wall did not change much from the Tang Dynasty onward. Suzhou private gardens had experienced changes from fewer to greater in number, from large to small in scale, from the city center to the north and south and outside the Chang Gate in distribution, and from natural to artificial in layout. In the Tang and Song Dynasties, water source and traffic affected garden site selection. There were many available plots of land within the city, so the richest of Suzhou's citizens built many large-scale gardens hundreds of mu in size. After the Ming Dynasty, Suzhou transformed from a military city to an industrial and commercial city. The influence of government buildings on the distribution of gardens weakened with the disappearance of the castle, and it became more closely related to the formation and expansion of the commercial center in the northwest of the city. Meanwhile, with the increase in the population and the fragmentation of the land, there were few large-scale plots of land available in the city, especially in the city center. During the Ming and Qing Dynasties, with the maturity of gardening theory and technology, it was easy to create rich visual experience in small gardens and courtyard gardens, making it possible for businessmen, literati and even doctors and actors with low economic strength to have private gardens. As a result, hundreds of courtyard gardens emerged alongside dozens of large- and medium-sized gardens, forming the scenery of 'half the city occupied by gardens'.

Supplementary Materials: The following are available online at https:/ / www.mdpi.com/2073-445 X/10/3/281/s1, Table S1: Information of garden owners and others.

Author Contributions: Conceptualization, T.Z.; methodology, T.Z.; software, T.Z.; validation, T.Z., formal analysis, T.Z.; investigation, Z.L.; resources, T.Z.; data curation, Z.L.; supervision, T.Z.; project administration, T.Z.; funding acquisition, T.Z. All authors have read and agreed to the published version of the manuscript.

Funding: This research was funded by Humanities and Social Science Fund of Ministry of Education of China, grant number 20YJC760131. 
Institutional Review Board Statement: Not applicable.

Informed Consent Statement: Not applicable.

Data Availability Statement: The data presented in this study are available on request from the author. The data are not publicly available due to [privacy]. Images employed for the study will be available online for readers.

Acknowledgments: The authors acknowledge the Local Chronicles Archives of Suzhou, Suzhou Library, Suzhou Garden Archives, and Suzhou Garden and Greening Administration Bureau for their kind help.

Conflicts of Interest: The authors declare no conflict of interest.

\section{References}

1. Fan, C. Wu Jun Zhi; Zhengxing, X., Ed.; Jiangsu Classics Publishing House: Nanjing, China, 1999; p. 660.

2. Zhao, Y. Wu Yue Chun Qiu; The Commercial Press: Shanghai, China, 1937; p. 41.

3. Lu, G. Wu Di Ji; Zhonghua Book Company: Beijing, China, 1985; p. 8.

4. Liu, D. Chinese Classical Gardens of Suzhou; Joseph, C.W., Ed.; McGraw-Hill: New York, NY, USA, 1993 ; pp. 11-20.

5. Bai, Q. A preliminary study of relationship between 'Chengshi (City)' and 'Shanlin (Landscape)' in Chinese ancient literature. Chin. Landsc. Arch. 2019, 2, 125-128.

6. Maggie, K.; Charles, J.; Alison, H. The Chinese Garden: History, Art and Architecture; Harvard University Press: Boston, MA, USA, 2003; p. 7.

7. $\mathrm{Wu}$, J. Jiangnan Gardens and Urban Society: A Social-Historical Analysis of Suzhou Gardens during the Ming and Qing Dynasties. Available online: http:/ / www.mh.sinica.edu.tw /MHDocument/PublicationDetail/PublicationDetail_99.pdf (accessed on 31 January 2021).

8. $\mathrm{Xu}, \mathrm{Y}$. Boundaries, centres and peripheries in Chinese gardens: A case of Suzhou in the eleventh century. Stud. Hist. Gard. Des. Lands 2012, 24, 21-37. [CrossRef]

9. Mei, J. ‘Su Cheng Hao, Cheng Li Ban Yuan Ting' Qianlong Gusu Cheng Tu Zhong Yuanlin Yongdi Guimo Ji Fenbu Yanjiu. J. Chin. Arch. Hist. 2010, 3, 217-504.

10. Chen, Y. Xingtai, Leixing Yu Yiyi: Suzhou Gucheng Xingtai Yanhua Yanjiu; Southeast University Press: Nanjing, China, 2006; pp. 31-33.

11. Chen, C. Bianqian Zhong De Yuanlin-Mingdai Yihou Suzhou Yuanlin Jianzhu Mianji De Bianhua Yu Diqu Renkou Biandong De Gualian. Xin Shiji Luncong 2006, 2, 9-11.

12. Gu, G.; Yu, C.; Li, L.; Hong, D. The research of changes of the chinese cistorical private classical carden and the authenticity of the protection-A case study of the Yiyuan. J. Hum. Settl. West. China 2018, 5, 69-77.

13. Ye, T.; Fang, H. Research on the historic appearance of the Lion Grove from the Yuan dynasty to the Republic of China. Stud. Hist. Gard. Des. Lands 2017, 37, 1-14. [CrossRef]

14. Zhang, T.; Wang, H.; Lian, Z. Research on the preservation and continuation of private gardens in Suzhou in perspective of the history changes of Canglang Pavilion. Chin. Landsc. Arch. 2018, 2, 133-137.

15. Qu, W. Suzhou Hedao Zhi; Jilin People's Publishing House: Changchun, China, 2007.

16. Olivia, M. Urbanization in Early and Medieval China: Gazetteers for the City of Suzhou; University of Washington Press: Seattle, WA, USA, 2015; p. 89.

17. Zhang, Y. The Atlas of Ancient Suzhou; Gu Wu Xuan Publishing House: Suzhou, China, 2004.

18. Fu, W. Tang Hui Yao; Zhonghua Book Company: Beijing, China, 1955; p. 1239.

19. Lu, G. Bai Ou Shi Xu. In Suzhou Yuanlin Lidai Wenchao; Yi, X., Ed.; SDX Joint Publishing Company: Shanghai, China, $2008 ;$ p. 1.

20. Wang, J. Song Pingjiang Chengfang Kao; Jiangsu Classics Publishing House: Nanjing, China, 1999; p. 35.

21. Yuan, L. Songdai Chengshi Xingtai He Guanshu Jianzhu Zhidu Yanjiu; China Architecture \& Building Press: Beijing, China, 2013; p. 78.

22. Wei, J. Suzhou Gudian Yuanlin Shi; SDX Joint Publishing Company: Shanghai, China, 2006; p. 181.

23. Gong, M. Zhong Wu Ji Wen; Zhonghua Book Company: Beijing, China, 1985; pp. 87-89.

24. Xu, D. Jin Yu Lu. Available online: https:/ / fzk.szlib.com/book/detail?bookId=219 (accessed on 31 January 2021).

25. Su, S. Cang Lang Ting Ji. In Suzhou Yuanlin Lidai Wenchao; Yi, X., Ed.; SDX Joint Publishing Company: Shanghai, China, $2008 ;$ p. 4.

26. Conzen, M.R.G. Alnwick, Northumberland: A Study of Town-Plan Analysis; Institute of British Geographers Publication: London, UK, 1960; p. 27.

27. Wang, A. Gusu Zhi; Bibliography and Document Publishing House: Beijing, China, 1990; p. 262.

28. Fan, J.; Xia, W. Suzhou Diqu Shehui Jingji Shi Mingqing Juan; Lun, L., Ed.; Nanjing University Press: Nanjing, China, 1993; pp. 61-82.

29. Dai, M. Lyu Yin Zhai Gu Gui Ji. In Suzhou Yuanlin Lidai Wenchao; Yi, X., Ed.; SDX Joint Publishing Company: Shanghai, China, 2008; p. 111.

30. Li, D. Dong Zhuang Ji. In Suzhou Yuanlin Lidai Wenchao; Yi, X., Ed.; SDX Joint Publishing Company: Shanghai, China, 2008; pp. 9-60. 
31. Xu, Y. Ruyi Tang Ji. In Suzhou Yuanlin Lidai Wenchao; Yi, X., Ed.; SDX Joint Publishing Company: Shanghai, China, $2008 ;$ pp. 19-20.

32. Han, Y. Feng Xi Cao Tang Ji. In Suzhou Yuanlin Lidai Wenchao; Yi, X., Ed.; SDX Joint Publishing Company: Shanghai, China, 2008; p. 58.

33. Wang, S. Wan Pu Ji. In Suzhou Yuanlin Lidai Wenchao; Yi, X., Ed.; SDX Joint Publishing Company: Shanghai, China, 2008; p. 60.

34. Li, G.; Gu, Y. (Qianlong) Changzhou Xian Zhi; Jiangsu Classics Publishing House: Nanjing, China, 1991; p. 184.

35. Tang, C. Huang Huang Zhai Ji bing Ming. In Suzhou Yuanlin Lidai Wenchao; Yi, X., Ed.; SDX Joint Publishing Company: Shanghai, China, 2008; p. 73.

36. Jiang, Y. Hou Le Tang Ji. In Suzhou Yuanlin Lidai Wenchao; Yi, X., Ed.; SDX Joint Publishing Company: Shanghai, China, 2008; p. 50.

37. Gui, Z. Ba Jiang Gei Jian Bian E Hou. In Suzhou Yuanlin Lidai Wenchao; Yi, X., Ed.; SDX Joint Publishing Company: Shanghai, China, 2008; p. 69.

38. Xu, Y. The Scroll of the Flourishing Times; Liaoning Provincial Museum, Ed.; Cultural Relics Publishing House: Beijing, China, 1986.

39. Niu, R.; Wang, H. (Chongzhen) Wu Xian Zhi. Available online: https:/ / fzk.szlib.com/book/detail?bookId=22 (accessed on 31 January 2021).

40. Qian, Y. Lyu Yuan Cong Hua; Shanghai Classics Publishing House: Shanghai, China, 2012; p. 8.

41. Henderson, R. The Gardens of Suzhou: Penn Studies in Landscape Architecture; University of Pennsylvania Press: Philadelphia, PA, USA, 2013.

42. Ruggia, J. Heaven Above, Suzhou Below. Travel Agent 2002, 310.

43. Dunzhen, L. History of Ancient Chinese Architecture; China Architecture \& Building Press: Beijing, China, $1980 ;$ p. 164.

44. Yi, W. Zhongguo Yuanlin Wenhua Shi; Shanghai People Publisher: Shanghai, China, 2004; pp. 445-457.

45. Qishou, D. Suzhou Yuanlin Shanshuihua Xuan; SDX Joint Publishing Company: Shanghai, China, 2007; pp. 16-28.

46. Wang, S. Qiu Zhi Yuan Ji. In Suzhou Yuanlin Lidai Wenchao; Yi, X., Ed.; SDX Joint Publishing Company: Shanghai, China, 2008; p. 66.

47. Feng, G. (Tongzhi) Suzhou Fu Zhi; Cheng Wen Publishing House: Taipei, Taiwan, 1983; p. 1284.

48. Wen, Z. Wen Zhengming Ji; Shanghai Classics Publishing House: Shanghai, China, 1987; Volume 12, p. 333.

49. Yi, X.; Chen, W. (Eds.) Ou Yuan Zhi; Wen Hui Press: Shanghai, China, 2013; pp. 1-2.

50. Keswick, M.; Charles, J.; Alison, H. The Chinese Garden: History, Art and Architecture; Maggie, K., Ed.; Harvard University Press: Cambridge, MA, USA, 2003; pp. 6-12.

51. Wan, W. Shao Hua Shu Wu Ji. In Suzhou Yuanlin Lidai Wenchao; Yi, X., Ed.; SDX Joint Publishing Company: Shanghai, China, 2008; p. 110.

52. Wang, J. Tui Yuan Bu Ji. In Suzhou Yuanlin Lidai Wenchao; Yi, X., Ed.; SDX Joint Publishing Company: Shanghai, China, 2008; p. 108.

53. Zhu, S. Yi Ju Tu Ji. In Suzhou Yuanlin Lidai Wenchao; Yi, X., Ed.; SDX Joint Publishing Company: Shanghai, China, $2008 ;$ p. 106.

54. Jiang, G. Xiu Gu Ji. In Suzhou Yuanlin Lidai Wenchao; Yi, X., Ed.; SDX Joint Publishing Company: Shanghai, China, 2008 ; p. 104.

55. Wu, Y. Dong Zhai Ji. In Suzhou Yuanlin Lidai Wenchao; Yi, X., Ed.; SDX Joint Publishing Company: Shanghai, China, $2008 ;$ p. 103.

56. Yuan, X. Shuang Ta Ying Yuan Ji. In Suzhou Yuanlin Lidai Wenchao; Yi, X., Ed.; SDX Joint Publishing Company: Shanghai, China, 2008; p. 83.

57. You, D. Shui Zhai Xuan Ji. In Suzhou Yuanlin Lidai Wenchao; Yi, X., Ed.; SDX Joint Publishing Company: Shanghai, China, 2008; p 80 .

58. Qian, Z. Suzhou Gucheng Bianqian Lue Lun. In Suzhou Lishi Xuehui Wenxuan; Suzhou Historical Institute: Suzhou, China, 1983; pp. 98-106.

59. Lu, X. (Hongwu) Suzhou Fu Zhi; Cheng Wen Publishing House: Taipei, Taiwan, 1983; p. 421.

60. Shuji, C. Hongwu Shiqi Dongnanfu, Xianzhi Chengshi Renkou Shuliang Yanjiu-Yi Jingshi, Fujian He Jiangxi Weili. Res. Chin. Econ. Hist. 1999, 1, 19-33.

61. Ya Er, H.S. (Qianlong) Suzhou Fu Zhi. Available online: https://fzk.szlib.com/book/detail?bookId=35 (accessed on 31 January 2021).

62. Song, R.; Shi, W. (Daoguang) Suzhou Fu Zhi. Available online: https://fzk.szlib.com/book/detail?bookId=23 (accessed on 31 January 2021).

63. Wang, W. Wu Wenhua Yu Jiangnan Shehui Yanjiu; Qunyan Press: Beijing, China, 2005; p. 285.

64. Zhang, G. Wuzhong Shuili Quanshu. Available online: http:/ / reader.szlib.com/opac/book/ 610780 (accessed on 31 January 2021).

65. Craig, C. Fruitful Sites: Garden Culture in Ming Dynasty China; Duke University Press: Durham, NC, USA, 1996 ; p. 16.

66. Chen, J. Yi Yuan. In Yi Yuan Zhi; Yi, X., Chen, W., Eds.; Wen Hui Press: Shanghai, China, 2013.

67. San Ren, Y.L.; Shi, Z. Yuan Yi; Architecture \& Building Press: Beijing, China, 2013; pp. 3-38.

68. Bureau of Suzhou Real Estate Management. Ancient Residences in Suzhou; Tongji University Press: Shanghai, China, $2004 ;$ p. 187.

69. Yu, Y. Qingdai Guanzhi Yu Fushi; Liaoning Nationality Publishing House: Shenyang, China, 2009; p. 68.

70. Chen, C. Traditional Suzhou Dwellings; SDX Joint Publishing Company: Shanghai, China, 2003; p. 153. 